\title{
Time as a factor during endoscopic assessment of swallowing: relevance in defining the score and severity of swallowing disorders
}

\author{
Il tempo come fattore durante la valutazione endoscopica della deglutizione: \\ la sua rilevanza nel definire il punteggio e la gravità dei disturbi della deglutizione \\ D. FARNETI ${ }^{1}$, B. FATTORI ${ }^{2}$, L. BASTIANI ${ }^{3}$ \\ ${ }^{1}$ Audiology and Phoniatrics Department, Romagna Health Service, Rimini Hospital, Italy; ${ }^{2}$ ENT Department, Audiology \\ and Phoniatrics, Pisa University, Italy; ${ }^{3}$ Institute of Clinical Physiology, National Council of Research (CNR), Pisa, Italy
}

\begin{abstract}
SUMMARY
Time is a parameter of great interest in swallowing and can be considered in different ways to express severity during endoscopic evaluation. The objectives of this study are to evaluate how the severity of this score changes at different times of scoring and the interaction between residue persistence and airway invasion. Two experienced raters blindly evaluated 35 short clips of bolus transit that were recorded during endoscopic evaluations of 16 patients with dysphagia of differing aetiologies. The pooling score (p-score) and the Penetration Aspiration Scale (PAS) were detected after the first swallowing (T1) and after the fifth dry swallow (T5). For each task, the time needed to complete the clearing of the bolus (total time: TT) was blindly determined by the two raters and compared with the Functional Oral Intake Scale (FOIS) and Dysphagia Outcome and Severity Scale (DOSS) scales, previously detected.The inter-rater agreement between the 2 raters in scoring the p-score and PAS was good (ICC $>0.800$ ) for T1 vs T1 and T1 vs T5, and in determining TT for each consistency (ICC > 0.9), with a Spearman's Rho > 0.70 and > 0.90 respectively. A statistical correlation of the p-score total, TT and consistency with FOIS and DOSS was found. The p-score showed a good trade-off between sensitivity and specificity compared with the PAS aspiration and penetration scores. The time of scoring (T1 vs T5) is relevant in detecting severity of dysphagia during endoscopic evaluation. The time spent to clear residue is a useful parameter and is correlated with severity of dysphagia expressed by the p-score and with functional swallowing status in dysphagic patients. The p-score is correlated with the PAS score in detecting airway invasion.
\end{abstract}

KEY WORDS: Swallowing • Deglutition disorders $\bullet$ Endoscopy $\bullet$ Aspiration $\bullet$ Residue $\bullet$ Severity

\section{RIASSUNTO}

Il tempo è un parametro di grande interesse nella deglutizione variamente considerato per esprimere gravità durante una valutazione endoscopica. Gli obiettivi del lavoro sono di valutare come la gravità di un punteggio cambia in diversi tempi di rilevazione e l'interazione tra persistenza di residui e invasione delle vie aeree. Due valutatori esperti hanno valutato in cieco 35 brevi filmati di transiti faringei di bolo, registrati durante valutazioni endoscopiche di 16 pazienti con disfagia a differente eziologia. Il punteggio del pooling score (p-score) e la Penetration Aspiration Scale (PAS) sono stati rilevati dopo la prima deglutizione (T1) e dopo la quinta (T5). Per ogni transito, il tempo necessario per completare la detersione del bolo (tempo totale: TT) è stato determinato in cieco dai due valutatori e confrontato con le scale Functional Oral Intake Scale (FOIS) and Dysphagia Outcome and Severity Scale (DOSS) scales, precedentemente determinate. L'affidabilità inter-rater tra i 2 valutatori nel punteggio del p-score e PAS è stata buona $($ ICC > 0,800) per T1 vs T1 e T1 vs T5, e nel determinare TT per ogni consistenza (ICC > 0,9), con Rho di Spearman > 0,70 e > 0,90 rispettivamente. È stata trovata una correlazione statistica fra il p-score totale, TT, e la consistenza con il FOIS e il DOSS. Il p-score ha mostrato un buon trade-off tra sensibilità e specificità rispetto ai punteggi PAS che esprimono aspirazione e penetrazione. Il tempo di applicazione di una scala (T1 vs T5) è rilevante nel determinare la severità della disfagia durante una valutazione endoscopica. Il tempo impiegato dal paziente per detergere i residui è un parametro utile da determinarsi ed è correlato alla gravità della disfagia espressa dal p-score e allo stato funzionale di pazienti disfagici. Il p-score è correlato al punteggio PAS nel rilevare l'invasione delle vie aeree.

PAROLE CHIAVE: Deglutizione $\bullet$ Disturbi della deglutizione $\bullet$ Endoscopia $\bullet$ Aspirazione $\bullet$ Ristagni $\bullet$ Gravità

\section{Introduction}

In normal conditions, the progression of the bolus through the upper digestive tract must meet criteria of efficiency and effectiveness: any condition that deviates from these criteria generates an unsafe swallowing act with nasal regurgitation, penetration, aspiration, or an inefficient swallowing act, with residue of bolus ${ }^{1}$. These two conditions can coexist and influence each other: a bolus that leaves residue in the pharynx can be cleared or can invade the 
upper airway during a subsequent swallowing act ${ }^{2}$, while a bolus invading the upper airway can indefinitely remain in the larynx or cervical trachea. Instrumental investigation must be able to document these conditions, with the aim of defining criteria of severity that better indicate, in a clinical context, the risk of respiratory or nutritional complications ${ }^{34}$. This same information, in the short term, is useful in planning therapeutic strategies and in reducing long-term complications ${ }^{5}$. Today, several tools are available to evaluate and quantify ineffective or inefficient swallowing. Some tools designed for the radiological setting have been adapted and applied to endoscopic examination. An example is the penetration aspiration scale (PAS) ${ }^{6}$, originally designed for the modified barium swallow (MBS) and subsequently replicated for endoscopy ${ }^{7-10}$. The PAS is widely used to define the entity of airway invasion and possible ejection attempts. The PAS score is applied after the first/second swallow, without a standard reported in the literature or in the original paper ${ }^{6}$. However, in clinical practice, more varied conditions can be found. A bolus can be propelled by more swallowing acts (multiple swallowing) or coexist with residue, imposing several dry swallows before clearing. In these conditions, airway invasion may occur after the swallow ${ }^{11}$ or require defensive strategies (spontaneous or requested) carried out over a longer period of time (more than one or two dry swallows).

In the literature, some rating scales are applied after the first-second swallowing acts, such as the aforementioned PAS, and others after the second one, such as the pooling score (p-score) ${ }^{12}$ and Boston Residue and Clearance Scale ${ }^{13}$. Some scales do not mention the time of scoring ${ }^{8}$ and others leave the decision to the clinician as to when to score ${ }^{14-18}$. The first tool proposed, to be applied after the second swallow, was the p-score, a validated scale 1219 that considers 5 dry swallows before scoring residue in the pharyngeal or laryngeal cavities. The total score derives from the sum of partial scores attributed to the anatomical site where material is pooling, its amount (semiquantitatively compared to the volume's bidimensional viewing of the cavities) and to the number and effectiveness of dry swallowing, or other strategies, performed in the attempt to clear residue ("management" of residue, see Table I). The score expresses a continuum of severity which, in clinical practice, can be spread over four levels, describing different levels of clinical severity (Table I). The consistency of the bolus does not seem to affect the score ${ }^{19}$. The p-score, like the other scores, does not consider the parameter 'time', i.e. the time necessary to clear the bolus or to complete the 5 dry swallows requested, but focuses on the residue and the correlates that define it.
Table I. Pooling score (p-score).

\begin{tabular}{|c|c|c|}
\hline Pooling & \multicolumn{2}{|c|}{ Endoscopic landmark } \\
\hline \multirow[t]{4}{*}{ Site } & Vallecule - marginal zone & 1 \\
\hline & Pyriform sinus & 2 \\
\hline & Vestibule - vocal cords & 3 \\
\hline & Below the vocal cords & 4 \\
\hline \multirow[t]{3}{*}{ Amount } & Coating & 1 \\
\hline & Minimum & 2 \\
\hline & Maximum & 3 \\
\hline \multirow[t]{3}{*}{ Management } & $<2$ & 2 \\
\hline & $2><5$ & 3 \\
\hline & $>5$ & 4 \\
\hline Score & P 4-11 & \\
\hline \multicolumn{3}{|c|}{$\begin{array}{l}\text { "Pooling" any material that dwells or coats the hypopharynx and/or larynx cavities } \\
\text { before/after swallowing. Site: anatomical landmark in a cranio-caudal direction } \\
\text { Amount: volumetric ratio between content and container (minimally filled, less thar } \\
\text { half or more than half). Management: any spontaneous/reflex activity adopted to clea } \\
\text { pooling (dry swallows, gurgling, clearing and cough). p- score: } 4-5=\text { minimum score } \\
\text { corresponding to no endoscopic signs of dysphagia; } 6-7=\text { low score, corresponding } \\
\text { to mild dysphagia; } 8-9=\text { middle score, corresponding to moderate dysphagia; } 10 \\
11=\text { high score, corresponding to severe dysphagia }\end{array}$} \\
\hline
\end{tabular}

Swallowing times during endoscopic evaluation of swallowing have been assessed in several studies ${ }^{20-25}$ and time association with swallowing abnormalities was explored in some of them ${ }^{22-25}$. Nevertheless, the time considered in those investigations does not include the time needed to clear residue, a parameter which has previously been considered in our preliminary report ${ }^{26}$. Cinical observations, indeed, show conditions where the material pooling is cleared in a few seconds and other conditions where a longer time is needed to match this goal, provided that it is possible. In this context, the time of 'management' of the residue recalls the attempts to clear saliva with spontaneous swallowing acts performed by elderly patients ${ }^{15}$ or stroke patients ${ }^{27}$, although different pressure and awareness are required to clear residue. This perspective leads to a parameter of severity where the clearing time can become a marker of effectiveness of the swallowing act in pathological conditions or where its increase, under stress, can become a marker of fatigue ${ }^{28}{ }^{29}$. If this were true, the time of 'management' could vary similarly to the variation of other scales ${ }^{26}$ such as the Functional Oral Intake Scale (FOIS) ${ }^{30}$ and the Dysphagia Outcome and Severity Scale (DOSS) ${ }^{31}$.

With these considerations in mind, the aims of this study are to evaluate: 1 ) if the p-score changes when applied before the fifth swallowing act and whether the PAS changes when applied after the first; 2 ) the reliability of 2 raters in scoring residue at different times and their reliability in determining these times (time of 'management' of the pscore); 3 ) possible correlation of PAS to p-score. 


\section{Materials and methods}

In a prospective way, 16 consecutive outpatients $(11 \mathrm{M} / 5 \mathrm{~F}$, mean age 63.94 years \pm 15.46 , range $25-88$ ) were submitted to a fibreoptic endoscopic evaluation of swallowing (FEES) ${ }^{32}$. The patients were complaining of swallowing disorders due to different aetiologies (Table II). Inclusion criteria were: over 18 years old, an instrumentally documented impaired swallow (residue, false routes), compliance to the endoscopic procedure; exclusion criteria were: less than 18 years old and non-compliance to the endoscopic procedure. The patients with low dysphagia were considered because they respected the criteria of inclusion. FEES was performed with a Storz endoscope (model 11101RP2, $30 \mathrm{~cm}$ long, $3.5 \mathrm{~mm}$ in diameter) and recorded with a workstation (Xion medical products Gm$\mathrm{bH}$, Berlin Buchholz). During FEES and with the endoscope in place, one bolus of each consistency was given to each patient: $5 \mathrm{cc}$ pureed (P), $1 / 4$ of a cracker (regular-R) and $5 \mathrm{cc}$ liquid $(\mathrm{L})^{33}$. The patients prepared the bolus and swallowed without any command. Some patients were not able to test all three consistencies, owing to the severity of their complaint. For each patient, short videos were obtained for each swallowing trial so that a total of 35 clips were collected and reviewed by two expert raters (with more than 15 years' experience in performing FEES) in a blind manner. The raters were requested to score each bolus trial with the p-score and the PAS. Both the p-score and the PAS score were applied after the first (time 1-T1) and fifth swallow (time 5-T5). In this way, the parameter

Table II. Case series.

\begin{tabular}{llcc} 
Pts n. & Main pathology & Gender & Age \\
\hline 1 & Arnol-Chiari malformation & M & 56 \\
2 & MSA-P & M & 85 \\
3 & Myasthenia gravis & M & 73 \\
4 & Vascular dementia & M & 74 \\
5 & Parkinson's disease & M & 75 \\
6 & TBl sequelae & M & 44 \\
7 & Oesophageal dysphagia & F & 72 \\
8 & Supraglottic laryngectomy & F & 80 \\
9 & Stroke sequelae & M & 88 \\
10 & Parkinson's and ictus & M & 81 \\
11 & Cervical hyperostosis & M & 84 \\
12 & Steinert syndrome & M & 69 \\
13 & Klinefelter syndrome & M & 25 \\
14 & Cerebral palsy & F & 26 \\
15 & Subtotal laryngectomy & F & 58 \\
16 & Multiple sclerosis & F & 33 \\
\hline
\end{tabular}

'management' of the p-score was always the minimum provided by the score. The raters also blindly determined the time necessary to perform the 5 dry swallowing acts (total time: TT). TT was timed with a stopwatch in iOS 9.0, 4+ (Tim O's Studios, LLC) at the beginning of the first white-out and at the conclusion of the fifth whiteout ${ }^{34}$. In accordance with the $\mathrm{p}$-score, spontaneous and cued dry swallows were considered. TT was compared with the patients' ability for oral intake of food and liquid, measured against the Functional Oral Intake Scale (FOIS), even if only validated for stroke patients ${ }^{30}$ and the functional severity of dysphagia measured against the Dysphagia Outcome and Severity Scale (DOSS) ${ }^{31}$. The scales were previously determined by rater 1 . Because of the small sample, monovariate analysis was previously performed among TT and consistencies (explanatory variables) and FOIS and DOSS, respectively. Subsequently, multiple linear regression, considering FOIS and DOSS as dependent variables, was performed taking into account the TT, p-score total and consistency.

The intra-class correlation coefficient was performed to evaluate the inter-rater reliability of the two raters for FEES at T1 and T5 (ICC) and determine TT. In accordance with the literature, the following were considered for ICC values: 0-0.2 poor; 0.3-0.4 fair; 0.5-0.6 moderate; 0.7-0.8 strong; and $>0.8$ almost perfect. For each rater, the Rho Spearman's coefficient $(r>0.70$-sing $<0.05$ ) was performed to evaluate the correlation between PAS and pscore and TT. Furthermore, in order to determine optimal thresholds for the p-score when compared to PAS diagnoses, the Receiver Operator Characteristic (ROC) curve analysis was performed after dichotomising PAS between penetration scores 2 to 5 and aspiration scores 6 to 8 . To determine the best balance between sensitivity and specificity, the Youden Index (Y = sensitivity+specificity-1), was chosen as the criterion for cut-off value selection. All statistical analyses were performed using SPSS v.21.0 (IBM Corp., Armonk, NY, USA) and STATA version 13 (STATA Corp., TX, USA).

All patients gave their written consent to the procedures, in accordance with the Declaration of Helsinki. The study was approved by the local Ethical Research Committee.

\section{Results}

The mean times necessary to clear residue for $\mathrm{P}, \mathrm{R}$ and $\mathrm{L}$ were 22.5 secs (range 4-42), 30.7 secs (range 11-44) and 16.6 secs (range 8-33), respectively, with a mean TT of $53.8 \mathrm{sec}$. The inter-rater agreement between the 2 raters in scoring the p-score and PAS was good (ICC > 0.800) for each consistency and time of scoring (T1 vs T1 and 
T1 vs T5) with the exception of the liquid bolus. The inter-rater agreement between the 2 raters in detecting TT was good (ICC $>0.9$ ) for each consistency (Spearman's Rho $>0.90$-sing < 0.001). A correlation between the PAS and the p-score at T1 vs T1 and T1 vs T5 was observed only for the pureed consistency for rater 1 and for pureed and liquid ones for rater 2 (Spearman's Rho $>0.70$-sing < 0.05). The linear regression model documented a significant correlation of the p-score total, TT and consistency with FOIS and DOSS. In particular, increasing the time spent in clearing residue corresponded to an increase in the p-score and decreased the FOIS for all consistencies; increasing the p-score decreased the DOSS score for R and L (Table III, IV). A good correlation between PAS score and p-score was found (Spearman's rho $0.924-\mathrm{P}<0.05)$. The screening properties of the p-score when compared to the PAS cut-off diagnosis of penetration (scores 2 to 5) and aspiration (scores 6 to 8 ) showed a good trade-off between sensitivity and specificity compared with the PAS aspiration scores (area under the $\mathrm{ROC}$ curve $=0,958 ; 95 \% \mathrm{CI}=0.784-0.994$ ) and with the PAS penetration scores (area under the ROC curve = $0.622 ; 95 \% \mathrm{CI}=0.352-0.792$ ), with a p-score cut-off of 3 for penetration and of 4 for aspiration, respectively.

\section{Discussion}

Our experience shows that when applying the p-score at T1 and the PAS at T5, with FEES, they correlate only for the $\mathrm{P}$ consistency for rater 1 and $\mathrm{P}$ and $\mathrm{L}$ for rater 2 . This leads us to consider that the lack of correlation between $\mathrm{T} 1$ and T5 suggests a real different value of the score applied, i.e. applying the PAS over the first swallowing act changes the score itself. It is also worth mentioning that for the liquid bolus there was no concordance between the two raters, contrary to the other consistencies.

The parameter 'time' also shows its importance under the quantitative perspective, as the time spent in completing a sequence of dry swallows. In our sample, the mean time necessary to clear residue for $\mathrm{P}, \mathrm{R}$ and $\mathrm{L}$ was far longer than the time physiologically reported in the literature for clearing boluses of the same consistency ${ }^{20-25}$. The detection of this parameter, in our experience, seems to be a reliable parameter worth including in endoscopic evaluation of swallowing ${ }^{26}$. The $\mathrm{p}$-score, which indirectly considers this parameter (residue 'management' in TT) enriched in that sense, may express a further criterion of severity (see Appendix). In our sample, the increase in TT is related to the increase in the p-score, and both are related to the decrease in the FOIS score for all consistencies tested and to the increase of the DOSS scale for R and $\mathrm{L}^{26}$.

Even the consistency, which does not affect the p-score ${ }^{19}$, when related to the TT, seems to be a parameter able to influence the outcome of the swallowing act (presence of residue) performed spontaneously or upon request by the patients in our sample. Increasing TT, a reduction in the efficiency of the swallowing act could be hypothesised: the fate of the residue during the TT is not predictable,

Table III. Linear regression models: relationship between TT and consistencies (explanatory variables) and FolS score (dependent variable).

\begin{tabular}{lcccc} 
& Beta & \multicolumn{2}{c}{ 95\% confidence interval } & P value \\
Fees - T - P tot & -1.321 & -4.649 & -0.635 & 0.029 \\
Fees - T - P sec & 1.128 & -0.022 & 1.216 & 0.053 \\
Fees - T - R tot & -1.927 & -0.801 & -1.494 & 0.004 \\
Fees - T - R sec & -2.437 & -0.370 & -0.171 & 0.007 \\
Fees - T - L tot & -0.439 & -0.505 & -0.080 & 0.027 \\
Fees - T - L sec & -0.903 & -0.113 & -0.050 & 0.007 \\
\hline
\end{tabular}

$T=$ time, $P=$ pureed, $R=$ regular, $L=$ liquid

Table IV. Linear regression models: relationship between TT and consistencies (explanatory variables) and DOSS score (dependent variable).

\begin{tabular}{lcccc} 
& Beta & \multicolumn{2}{c}{ 95\% confidence interval } & P value \\
Fees - T - P tot &,- 294 &,- 519 &, 208 &, 039 \\
Fees - T - P sec &, 025 &,- 034 & $-1,215$ &, 026 \\
Fees - T - R tot & $-1,338$ &,- 378 &,- 033 &, 024 \\
Fees - T - R sec &,- 931 &,- 173 &,- 047 &, 046 \\
Fees - T - L tot &,- 488 &,- 697 &,- 014 &, 030 \\
Fees - T - L sec &,- 634 &,- 101 & & \\
\hline
\end{tabular}

$T=$ time; $P=$ pureed; $R=$ regular; $L=$ liquid 
but it is plausible that it may be related to the aetiology/ comorbidities ${ }^{35} 36$. In this sense, a possible correlation between the p-score compared with PAS, in detecting penetration and aspiration, is expressed by the area under the ROC curves: these values indicate a good predictability of the p-score for the three consistencies in terms of sensitivity and specificity. The cut-off for aspiration is 4 and the cut-off for penetration is 3 , coinciding with the subparameter 'site' of the p-score, identifying residues below and above the vocal cords, respectively.

The main limitations of this work are the small sample and the different numerical representations of the bolus swallowed in different consistencies. Bearing this in mind, the work is intended to have a preliminary character, and to test the value of the 'time' parameter in defining the clinical severity of a swallowing disorder. Further research is in progress to correlate the tp-score with the fatigability of patients with swallowing disorders due to specific aetiologies.

\section{Conclusions}

The parameter 'time' was evaluated applying scores that consider directly ( $\mathrm{p}$-score) or indirectly (PAS) the bolus and its fate after subsequent swallowing acts (multiple swallows or cued swallows). The evaluation of FEES clips of swallowing tasks suggests how, by applying the p-score at T1 and PAS at T5, although for different consistencies, produced different scores between two expert raters. We conclude that the time of detection of a score modifies the score, so that the time of scoring (the first or subsequent swallowing act) should be previously defined and considered.

The time needed by the patient to clear the residue is a reliable parameter that correlates with the severity of the p-score and other scales that relate to the patients' functional status or with their deglutition skills, suggesting the possibility of a clinical use of the tp-score (Appendix) in the follow-up of patients with swallowing disorders due to specific aetiologies or after stressful swallowing activities (fatigue detection).

\section{Conflict of interest statement}

None declared.

\section{References}

1 Clavé P, Verdaguer A, Arreola V. Oropharyngeal dysphagia in the elderly. Med Clin (Barc) 2005;124:742-8.

2 Farneti D, Consolmagno P. Aspiration: the predictive value of some clinical and endoscopic signs. Evaluation of our case series. Acta Otorynolaryngol Ital 2005;25:36-42.
3 Farneti D, Genovese E. Endoscopic criteria in assessing severity of swallowing disorders. In: Speyer R, Bogaardt H, editors. Seminars in Dysphagia. London,UK: InTech; 2015. pp. 71-90.

4 Farneti D. The instrumental gold standard: FEES. J Gastroenterol Hepatol Res 2014;3:1281-91.

5 Brady S. Use of dysphagia severity scales during fiberoptic endoscopic exam of swallowing: treatment decisions and planning. ASHA Special Interest Division 13, Perspectives in Swallowing and Swallowing Disorders 2007;16:10-3.

6 Rosenbek JC, Robbins, J Roecker EV, et al. A Penetration-aspiration scale. Dysphagia 1996;11:93-8.

7 Colodny N. Interjudge and intrajudge reliabilities in Fiberoptic Endoscopic Evaluation of Swallowing (Fees $\left.{ }^{\circledR}\right)$ using the PenetrationAspiration Scale: a replication study. Dysphagia 2002;17:308-15. https://doi.org/10.1007/s00455-002-0073-4.

8 Kelly AM, Leslie P, Beale T, et al. Fibreoptic endoscopic evaluation of swallowing and videofluoroscopy: does examination type influence perception of pharyngeal residue severity? Clin Otolaryngol 2006;31:425-32. https://doi.org/10.1111/j.1749-4486.2006.01292.x.

9 Kelly AM, Drinnan MJ, Leslie P. Assessing penetration and aspiration: how do videofluoroscopy and fiberoptic endoscopic evaluation of swallowing compare? Laryngoscope 2007;11:1723-7. https://doi. org/10.1097/MLG.0b013e318123ee6a.

10 Pilz W, Vanbelle S, Kremer B, et al. Observers'agreement on measurements in fiberoptic endoscopic evaluation of swallowing. Dysphagia 2016;31:180-7. https://doi.org/10.1007/s00455-015-9673-7.

11 Molfenter SM, Steele CM. The relationship between residue and aspiration on the subsequent swallow: an application of the normalized residue ratio scale. Dysphagia 2013;28:494-500. https:// doi.org/10.1007/s00455-013-9459-8.

12 Farneti D. Pooling score: an endoscopic model for evaluating severity of dysphagia. Acta Otorhinolaryngol Ital 2008;28:135-40.

13 Kaneoka AS, Langmore SE, Krisciunas GP, et al. The Boston Residue and Clearance Scale: preliminary reliability and validity testing. Folia Phoniatr Logop 2013;65:312-7. https://doi. org/10.1159/000365006.

14 Neubeuer PD, Rademake AW, Leder S. The Yale Pharyngeal Residue Severity Rating Scale: an anatomically defined and imagebased tool. Dysphagia 2015;30:521-8. https://doi.org/10.1007/ s00455-015-9631-4.

15 Murray J, Langmore SE, Ginsberg S, et al. The significance of accumulated oropharyngeal secretions and swallowing frequency in predicting aspiration. Dysphagia 1996;11:99-103.

16 Park WY, Lee TH, Ham NS, et al. Endoscopist-directed flexible endoscopic evaluation of swallowing to the videofluoroscopic swallowing study increased the detection rates of penetration, aspiration, and pharyngeal residue. Gut Liver 2015;9:623-8. https://doi. org/10.5009/gnl14147.

17 Tohara H, Nakane A, Murata S, et al. Inter- and intra-rater reliability in fibroptic endoscopic evaluation of swallowing. J Oral Rehabil 2010;37:884-91. https://doi.org/10.1111/j.13652842.2010.02116.x.

18 Pilz W, Baijens LW, Passos VL et al. Swallowing assessment in myotonic dystrophy type 1 using fiberoptic endoscopic evaluation of swallowing (FEES). Neuromuscul Disord 2014;24:1054-62. https:// doi.org/10.1016/j.nmd.2014.06.002.

19 Farneti D, Fattori B, Nacci A, et al. The Pooling-score (P-score): inter- and intra-rater reliability in endoscopic assessment of the severity of dysphagia. Acta Otorhinolaryngol Ital 2014;3:105-10.

20 Dua KS, Ren J, Bardan E, et al. Coordination of deglutitive glottal function and pharyngeal bolus transit during normal eating. Gastroenterology 1997;112:73-83. 
21 Butler SG, Stuart A, Kemp S. Flexible endoscopic evaluation of swallowing in healthy young and older adults. Ann Otol Rhinol Laryngol 2009;118:99-106. https://doi. org/10.1177/000348940911800204.

22 Butler SG, Maslan J, Stuart A, et al. Factors influencing bolus dwell times in healthy older adults assessed endoscopically. Laryngoscope 2011;121:2526-34. https://doi.org/10.1002/lary.22372.

23 Tejima C, Kikutani T, Takahashi N, et al. Application of simple swallowing provocation test with fiberoptic endoscopic evaluation of swallowing in a cross-sectional study. BMC Geriatrics 2015;15: 48. https://doi.org/10.1186/s12877-015-0049-5.

24 Ursino S, Seccia V, Cocuzza P, et al. How does radiotherapy impact swallowing function in nasopharynx and oropharynx cancer? Short-term results of a prospective study. Acta Otorhinolaryngol Ital 2016;36:174-184. https://doi.org/10.14639/0392100X-640.

25 Wan P, Chen X, Zhu L, et al. Dysphagia post subcortical and supratentorial stroke. J Stroke Cerebrovasc Dis 2016;25:74-82. https://doi.org/10.1016/j.jstrokecerebrovasdis.2015.08.037.

26 Farneti D, Fattori B, Bastiani L. Residue and clearing time: preliminary considerations in defining dysphagia severity in daily practice. Hearing, Balance and Communication 2019. https://doi.org/10.108 0/21695717.2019.1631047.

27 Crary MA, Carnaby GD, Sia I, et al. Spontaneous swallowing frequency has potential to identify dysphagia in acute stroke. Stroke 2013;44:3452-7. https://doi.org/10.1161/STROKEAHA.113.003048.

28 Miller N, Noble E, Jones D, et al. Hard to swallow: dysphagia in Parkinson's disease. Age Ageing 2006;35:614-18. https://doi. org/10.1093/ageing/afl105.

29 Solomon NP. What is orofacial fatigue and how does it affect func- tion for swallowing and speech? Semin Speech Lang 2006;27:26882. https://doi.org/10.1055/s-2006-955117.

30 Crary MA, Carnaby-Mann GD, Groher ME, et al. Initial psychometric assessment of a functional oral intake scale for dysphagia in stroke patients. Arch Phys Med Rehabil 2005;86:1516-20. https:// doi.org/10.1016/j.apmr.2004.11.049.

31 O'Neil KH, MA, Purdy M, Falk J, et al. The Dysphagia Outcome and Severity Scale. Dysphagia 1999;14:139-45. https://doi.org/10.1007/ PL00009595.

32 Langmore SE, Schatz K, Olson N. Endoscopic and videofluoroscopic evaluations of swallowing and aspiration. Ann Otol Rhinol Laryngol 1991;100:678-81. https://doi.org/10.1177/000348949110000815.

33 Cichero JA, Steele C, Duivestein J et al. The need for international terminology and definitions for texture-modified foods and thickened liquids used in dysphagia management: foundations of a global initiative. Curr Phys Med Rehabil Rep 2013;24:280-91. https:// doi.org/10.1007/s40141-013-0024-Z.

34 Mozzanica F, Lorusso R, Robotti C, et al. Effect of age, sex, bolus volume, and bolus consistency on whiteout duration in healthy subjects during FEES. Dysphagia 2019;34:192-200. https://doi. org/10.1007/s00455-018-9961-0.

35 Farneti D, Turroni V, Genovese E. Aspiration: diagnostic contributions from bedside swallowing evaluation and endoscopy. Acta Otorhinolaryngol Ital 2018;38:511-6. https://doi. org/10.14639/0392-100X-1967.

36 Nordio S, Di Stadio A, Koch I, et al. The correlation between pharyngeal residue, penetration/aspiration and nutritional modality: a cross-sectional study in patients with neurogenic dysphagia. Acta Otorhinolaryngol Ital 2019 Mar 25. https://doi.org/10.14639/0392100X-2136 [epub ahead of print].

Received: March 30, 2019 - Accepted: April 26, 2019

\section{APPENDIX}

With respect to our sample, the time spent to clear the 3 consistencies tested ranges from 4 up to 44 seconds. Stratifying linearly this time on 9 levels of 5 seconds, a factor of correction (FOC) is obtained to adjust the p-score in the following way: $0-5$ secs $=+1,6-10$ secs $=+2,11-15$ secs $=+3,16-20$ secs $=+4,21-25$ secs $=+5,26-30$ secs $=+6,31-35 \operatorname{secs}=+7,36-40 \operatorname{secs}=+8,>40 \operatorname{secs}=+9$ (Table V). The sum of the p-score total + FOC represents the timed p-score (tp-score). In this new role, the tp-score ranges from 5 up to 20 , expressing itself as a continuum of severity ${ }^{26}$. The possibility of a clinical subdivision of the tp-score in further levels is under consideration.
Table V. Timed p-score ( $\mathrm{p}$-score)

\begin{tabular}{lcc} 
Pooling & Endoscopic landmark & \\
Site & Vallecule - marginal zone & 1 \\
& Pyriform sinus & 2 \\
& Vestibule - vocal cords & 3 \\
Below the vocal cords & 4 \\
Amount & Coating & 1 \\
& Minimum & 2 \\
Management & Maximum & 3 \\
& $<2$ & 2 \\
Score & $2><5$ & 3 \\
Time & $>5$ & 4 \\
\hline
\end{tabular}

Factor of correction (FOC): 0-5 secs $=+1,6-10$ secs $=+2,11-15$ secs $=+3,16-20$ secs $=+4,21-25$ secs $=+5,26-30$ secs $=+6,31-35$ secs $=+7,36-40$ secs $=+8$ $>40 \operatorname{secs}=+9$

How to cite this article: Farneti D, Fattori B, Bastiani L. Time as a factor during endoscopic assessment of swallowing: relevance in defining the score and severity of swallowing disorders. Acta Otorhinolaryngol Ital 2019;39:244-249. https://doi.org/10.14639/0392-100X-N0221

Address for correspondence: Daniele Farneti, Audiology and Phoniatrics Service, Infermi Hospital, via Settembrini 2, 47923 Rimini, Italy. Tel/Fax. +39 0541 705146. E-mail: lele.doc@libero.it 